\title{
Erratum to: Identification of the epitopes of monoclonal antibodies against P74 of Helicoverpa armigera nucleopolyhedrovirus
}

\section{The Virologica Sinica Staff}

Erratum to: VIROLOGICA SINICA 2013, 28 (6): 360-367

DOI 10.1007/s12250-013-3393-7

Published Online: 2 December 2013

In the original version of this article, one image in Figure 3 was a duplicate. Please see the correct Figure 3 here:

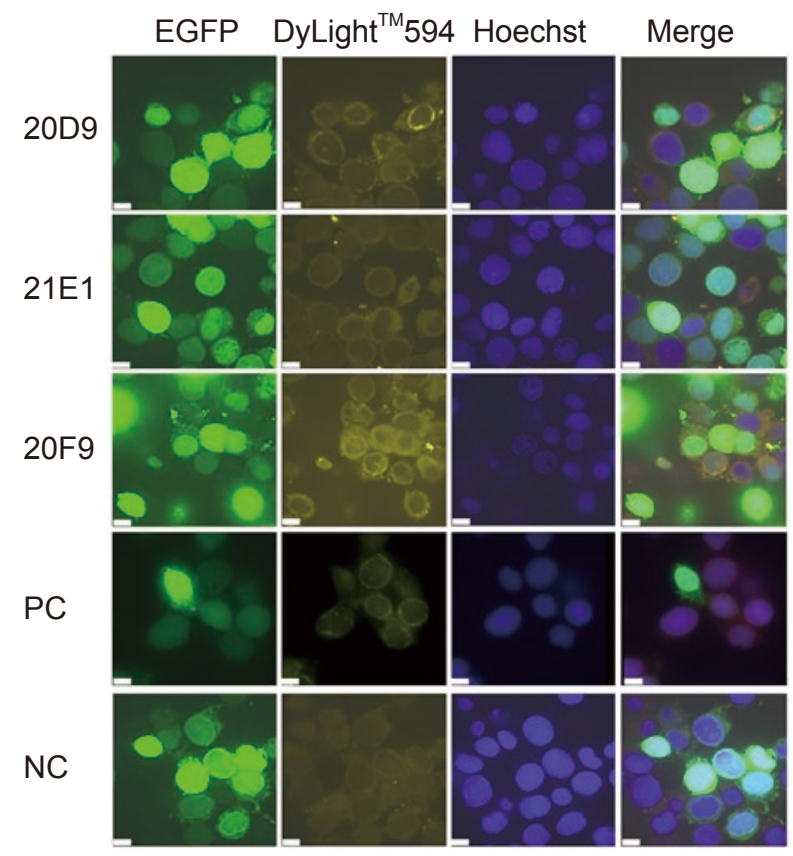

Figure 3. Recognition of P74 by mAbs 20D9 and 20F9 in HearNPV- infected cells. HzAM1 cells were infected with vHaBac-egfp-ph and, at $48 \mathrm{~h}$ p.i., cells were fixed in $4 \%(\mathrm{w} / \mathrm{v})$ formaldehyde. Immunofluorescence staining to detect HearNPV P74 (yellow) was performed using anti-P74 monoclonal antibodies and DyLight ${ }^{\mathrm{TM}}$ 594-conjugated goat anti-mouse lgG. Hoechst 33258 was used for staining of the nucleus. PC, anti-P74 polyclonal antibodies; NC, pre-immune serum. Scale bar $=10 \mu \mathrm{m}$. 